Article

\title{
Association of Aberrant DNA Methylation Level in the CD4 and JAK-STAT-Pathway-Related Genes with Mastitis Indicator Traits in Chinese Holstein Dairy Cattle
}

\author{
Tahir Usman ${ }^{1,2, *}$, Nawab Ali ${ }^{3}$, Yachun Wang ${ }^{1}\left(\mathbb{D}\right.$ and Ying Yu ${ }^{1, *}$ \\ 1 Key Laboratory of Agricultural Animal Genetics and Breeding, National Engineering Laboratory for Animal \\ Breeding, College of Animal Science and Technology, China Agricultural University, Beijing 100193, China; \\ wangyachun@cau.edu.cn \\ 2 College of Veterinary Science and Animal Husbandry, Abdul Wali Khan University, Mardan 23200, Pakistan \\ 3 Department of Zoology, Abdul Wali Khan University, Mardan 23200, Pakistan; nawabali79@gmail.com \\ * Correspondence: tahirusman@awkum.edu.pk (T.U.); yuying@cau.edu.cn (Y.Y.); Tel.: +92-313-092-0177 (T.U.); \\ +86-10-62-734-611 (Y.Y.); Fax: +86-10-62-732-439 (Y.Y.)
}

check for

updates

Citation: Usman, T.; Ali, N.; Wang, Y.; Yu, Y. Association of Aberrant DNA Methylation Level in the CD4 and JAK-STAT-Pathway-Related Genes with Mastitis Indicator Traits in Chinese Holstein Dairy Cattle. Animals 2022, 12, 65. https:// doi.org/10.3390/ani12010065

Academic Editors: Mahmoud M. Naguib, Mrigendra Rajput and Mehdi Soltani

Received: 17 November 2021 Accepted: 17 December 2021 Published: 29 December 2021

Publisher's Note: MDPI stays neutral with regard to jurisdictional claims in published maps and institutional affiliations.

Copyright: (C) 2021 by the authors. Licensee MDPI, Basel, Switzerland. This article is an open access article distributed under the terms and conditions of the Creative Commons Attribution (CC BY) license (https:// creativecommons.org/licenses/by/ $4.0 /)$.
Simple Summary: Mastitis is the most common inflammatory disease of economic and animal welfare concern in dairy animals. The present study was designed to evaluate the gene expression and epigenetic modifications in cattle with mastitis and healthy cows. The CpG islands in the promoter regions of the JAK2 and the STAT5A revealed hypo-methylation levels and higher gene expression in cows with mastitis compared to the healthy control, and vice versa in those with the CD4 gene. DNA methylation was negatively correlated with gene expression in the JAK2 and CD4 genes. Findings of the current study showed that aberrant DNA methylation due to mastitis in the promoter region of the three genes under study could be used as potential epigenetic markers to predict the mastitis susceptibility in dairy cattle.

\begin{abstract}
The present study was designed to evaluate the gene expression and DNA methylation level in the promoter region of the CD4 and the JAK-STAT-pathway-related genes. A total of 24 samples were deployed in the gene expression and 118 samples were used in the DNA methylation study. Student's $t$-tests were used to analyze the gene expression and DNA methylation. The evaluation of DNA methylation in promoter regions of JAK2 and STAT5A revealed hypo-methylation levels of CPG sites and higher gene expression in cows diagnosed with mastitis as compared to the healthy control, and vice versa in those with $C D 4$. DNA methylation was negatively correlated with gene expression in JAK2, STAT5A, and CD4 genes. Six, two, and four active transcription factors were identified on the CpG sites in the promoter regions of JAK2, STAT5A, and CD4 genes, respectively. Regarding correlation analysis, the DNA methylation levels of CD4 showed significantly higher positive correlations with somatic cell counts $(p<0.05)$. Findings of the current study inferred that aberrant DNA methylation in the CpG sites at the $1 \mathrm{~kb}$ promoter region in JAK2, STAT5A, and CD4 genes due to mastitis in cows can be used as potential epigenetic markers to estimate bovine mastitis susceptibility in dairy cattle.
\end{abstract}

Keywords: JAK-STAT pathway; DNA methylation; gene expression; epigenetic regulation; bovine mastitis resistance

\section{Introduction}

Mastitis is an inflammation of the mammary gland and is characterized by pathological, physiological and bacteriological changes in the udder which affect the quality and quantity of the milk [1]. Mastitis is the most common inflammatory disease of economic and animal welfare concern in dairy animals. Globally, published estimates of the economic losses of clinical mastitis per cow on a farm range from EUR 61 to EUR 97 [2]. In addition to economic importance, bovine mastitis also carries public health significance. Milk and 
other dairy products are often reported to be contaminated with S. aureus and E. coli. Milk from cows with sub-clinical mastitis accidentally mixed into bulk milk enters food chain, thus causing a great threat to human health [3]. The California mastitis test and somatic cell count are tests routinely performed for the detection of mastitis in dairy animals [4]. Large numbers of pathogens causing mastitis; therefore, successful vaccination to control the disease is not effective. Generally, antimicrobial agents and management strategies are used to combat the disease in dairy cattle [5]. However, marker-assisted selection using genetics and epigenetics approaches is considered an appropriate strategy to minimize the incidence of mastitis in dairy cattle [6,7].

DNA methylation is a biochemical process in which a methyl group is added to the $5^{\prime}$ carbon of cytosine in the CpG dinucleotide sequence of DNA by the catalytic activity of the DNA methyltransferases, i.e., DNMT1, DNMT3A and DNMT3B [8]. The epigenetic markers of DNA are heritable during cell division, and do not alter the DNA sequence. Aberrant DNA methylation at $\mathrm{CpG}$ islands in the gene promoter region results in transcriptional silencing and is associated with many disease conditions, i.e., cancer formation and tumor progression [9]. Aberrant DNA methylation suppresses the transcription by inhibiting the binding of specific TFs [10]. Hypomethylation of global DNA methylation induced by $S$. aureus infection suppressed DNA methyltransferase activity in bovine mammary epithelial cells [11].

The JAK-STAT pathway mediates signal transduction between nucleus and the cell surface receptors [12], and any disturbance in this inflammatory signaling pathway can result in various immune disorders such as immune deficiency syndromes, various cancer conditions, and mastitis in dairy animals $[13,14]$. CpG sites in JAK2 were hyper-methylated in myeloproliferative neoplasms compared with the healthy control, and $87.5 \%$ of the hyper-methylated CpG sites were located in the CpG island [15]. Our previous study demonstrated higher methylation levels of the $C D 4$ promoter region and lower gene expression in clinically mastitic cows compared with healthy controls using pyrosequencing assays and qRT-PCR [16]. CpG islands are CpG-rich areas in the promoter region of highly expressed genes and are a common site of methylation. Day and Bianco-Miotto (2013) [17] reported that CpG islands in around 55\% of cases form clusters and result in the inhibition or activation of transcription depending on the status of methylation. DNA methylation is the most understood mechanism amongst all epigenetic mechanisms. DNA methylation markings have been suggested to be relatively stable over time in adult individuals, showing average heritability of 0.19 [18], and are reported to play key roles in the regulation of gene activity, DNA repair, recombination, replication, and the establishment and maintenance of cellular identity [18]. Studies on mouse models have shown that the risk of tumor incidence can be transmitted across generations (up to three generations) through aberrant DNA methylation $[19,20]$. Due to the stable nature of DNA methylation across generations and its average heritability of 0.18-0.19 [21], it has been suggested to consider it as a potentially important epigenetic marker for selection in breeding programs. Therefore, we designed this study to evaluate the role of DNA methylation levels at the $1 \mathrm{~kb}$ promoter region in CD4 and JAK-STAT-pathway-related genes (JAK2, STAT5A, and STAT5B) in mastitic and healthy cows.

\section{Materials and Methods}

\subsection{Sample Collection and DNA Extraction}

Blood and milk samples were randomly collected from 118 lactating cattle (clinical mastitis, $n=58$; healthy control, $n=60$ ) from three Chinese Holstein dairy cattle farms (Qiqihar, Tianjin, and Shanxi) located in the northwest of China for DNA methylation analysis. The blood samples were collected in the morning between 9 a.m. and 11 a.m., whereas milk samples were collected at the routine milking time of 4 p.m. in the afternoon. A subset of 24 samples (of the total 118 samples) was used to evaluate the mRNA expression in the genes under study in mastitic and healthy cattle. We used routine dairy herd improvement (DHI) data to classify the different categories of lactating animal health status 
based on the SCC, i.e., healthy cows with SCC $<200,000 / \mathrm{mL}$, subclinical mastitis cows with SCC ranging between 200,000 and 500,000/mL, and cows with clinical mastitis had SCC $>500,000 / \mathrm{mL}$. The term "clinical mastitis" is used for cows with SCC $>500,000 / \mathrm{mL}$ based on the DHI data; however, these animals were apparently healthy and did not exhibit any clinical signs and symptoms. The healthy control represents lactating cows with healthy udders, without any history of mastitis in the last month, and SCC lower than 200,000/mL. The cows had different parities, ranging from parity one to five, and were milked three times per day (Table 1). The cattle were fed on a lactation diet as recommended by the Dairy Association of China for lactating cows (NRC2001). Milk samples were collected from all four quarters in sterile $50 \mathrm{~mL}$ falcon tubes and the SCC was analyzed at the official Dairy Center of China (Beijing, China). Blood samples were collected from the caudal vein of cows in three $9 \mathrm{~mL}$ tubes-one for serum isolation, the second for DNA extraction and the third for RNA extraction (the tubes contain pre-added TRIzol) - which were then immersed in liquid nitrogen at $-196{ }^{\circ} \mathrm{C}$ to avoid any damage to the RNA. Serum was isolated from blood samples by incubating the samples at room temperature for $30 \mathrm{~min}$ followed by centrifugation at $3000 \times g$ for $10 \mathrm{~min}$. The serum samples were then sent to Beijing Huaying Biological Technology Research Institute to evaluate serum biochemical assays of IL-4, IL-6, IL-10, IL-17, TNF- $\alpha$, and IFN- $\gamma$ using radioimmunoassay a technique, as described by Usman et al. (2017) [22].

Table 1. Information of the parity and health status of the samples used in the study.

\begin{tabular}{ccc}
\hline & Clinical Mastitis & Healthy Control \\
\hline Number & 58 & 60 \\
SCC * & $>500,000$ & $<200,000$ \\
Parity range & $1-5$ & $1-5$ \\
\hline
\end{tabular}

*SCC, somatic cell count.

\subsection{DNA and RNA Extraction, cDNA Synthesis, and Real-Time Quantitative PCR}

Genomic DNA and RNA extraction, reverse transcription of mRNA to CDNA, and realtime quantitative PCR were performed as described in our previous paper [14]. Primers were designed for JAK2, STAT5A, CD4, and GAPDH genes in Oligo 6.0 software, based on the golden rules for real-time PCR (Supplementary Materials Table S1) [23].

\subsection{Bisulfite Treatment of Extracted DNA and Hot Start PCR}

In order to evaluate the DNA methylation in JAK2, STAT5A, STAT5B, and CD4 genes, we first checked the presence of $\mathrm{CpG}$ islands in the promoter region of these genes using a genome browser (UCSC BAU 6.0). We found a CpG island located in the $1 \mathrm{~kb}$ promoter region of all genes except for STAT5B. Sequencing primers of the JAK2, STAT5A, and CD4 genes were designed with Oligo 6 software for evaluating DNA methylation in the genes under study (Supplementary Materials Table S2). Genomic DNA (1 $\mu \mathrm{g})$ of each sample was treated for sodium bisulfite conversion using the EZ DNA Methylation Golden kit, following the manufacturer's protocol (ZYMO Research, Irvine, CA, USA). A volume of $20 \mu \mathrm{L}$ elution buffer was used to elute the bisulfite-converted DNA (ZYMO Research). In our study, we used a biotin-labeled universal primer (5'-GGGACACCGCTGATCGTTTA$3^{\prime}$ ), as mentioned in our previous research [23]. A hot-start PCR was performed to amplify the target sequence in a $25 \mu \mathrm{L}$ volume, including $12.5 \mu \mathrm{L}$ hot-start PCR premix (ZYMO Research), $0.5 \mu \mathrm{M}$ forward primer, $0.05 \mu \mathrm{M}$ reverse primer labeled with universal tail, $0.45 \mu \mathrm{M}$ biotin-labeled universal primer, and $20 \mathrm{ng}$ bisulfite-converted DNA. The PCR protocol was $95{ }^{\circ} \mathrm{C}$ for $10 \mathrm{~min}, 94^{\circ} \mathrm{C}$ for $30 \mathrm{~s}, 50$ to $60{ }^{\circ} \mathrm{C}$ for $45 \mathrm{~s}$, and $72{ }^{\circ} \mathrm{C}$ for $45 \mathrm{~s}$, and a final extension at $72{ }^{\circ} \mathrm{C}$ for $10 \mathrm{~min}$ for a total of 45 cycles. The PCR products were checked by running them on $2 \%$ agarose gel stained with ethidium bromide for visualization. 


\subsection{Quantitative DNA Methylation Evaluation Using Pyrosequencing}

Pyrosequencing assays were conducted to quantitatively examine the methylation levels in the promoters of $J A K 2, S T A T 5 A$, and CD4 genes in clinically mastitic cows and healthy controls. The DNA methylation level was tested for the nine CpG sites in the JAK2 gene (USCS database: Bau6.0, Chr8: 39751199 39750253), seven CpG sites in the STAT5A gene (USCS database: Bau6.0, Chr19: 43033111 43034137), and five CpG sites located in the promoter region of the bovine CD4 gene (USCS database: Bau6.0, Chr5: 104015622 104015994). Pyrosequencing techniques were used to evaluate the promoter DNA methylation levels using a Pyro Q-CpG system (Qiagen), following the manufacturer's instructions. The high-quality purified DNA and the PCR products with high concentration (about 25 to $35 \mu \mathrm{L}$ ) were considered for pyrosequencing assays [24,25]. Streptavidin Sepharose High Performance (GE Healthycare) was utilized with the PCR products. The PCR products labeled with biotin and attached to Sepharose beads were distilled in $70 \%$ ethanol for $30 \mathrm{~s}$, denatured for $30 \mathrm{~s}$ in denature buffer $(0.2 \mathrm{M} \mathrm{NaOH})$, then washed for $45 \mathrm{~s}$ with washing buffer with the Pyrosequencing Vacuum Prep Tool (Qiagen). Subsequently, $0.5 \mu \mathrm{M}$ pyrosequencing primers of each gene was mixed with annealing buffer (Qiagen) in order to purify the PCR product. The methylation levels at each $\mathrm{CpG}$ site in the promoter region were revealed as the percentage $\left[\left({ }^{\mathrm{m}} \mathrm{C} /\left({ }^{\mathrm{m}} \mathrm{C}+\mathrm{C}\right)\right) \times 100\right]$. Here, ${ }^{\mathrm{m}} \mathrm{C}$ indicates methylated cytosine and $\mathrm{C}$ denotes unmethylated cytosine. In order to verify bisulfite conversion, non-CpG cytosine residues were used as internal controls.

\subsection{Statistical Analysis}

Student's $t$-tests were used for analyzing the mRNA expression (values from RT-qPCR) and DNA methylation between mastitic cows and healthy controls. Pearson's correlations of DNA methylation levels with mastitis-related traits in the genes under study were evaluated using the SAS (9.1) package. TFSEARCH software was used to predict the transcription factor binding sites in the promoter regions of the study genes.

\section{Results}

\subsection{CpG Sites Methylation in the Genes under Study}

The methylation statuses of $\mathrm{CpG}$ sites in the $\mathrm{CpG}$ island of the $1 \mathrm{~kb}$ promoter region in all genes under study were analyzed in mastitic cows and healthy controls using a pyrosequencing assay, except for the STAT5B gene, where no CpG island was present. The results of the pyrosequencing assay are shown below as methylation pyrogram (Figure 1). The pyrosequencing assay revealed aberrant methylation in almost all of the CpG sites in the genes under study (Table 2).

\subsection{Predicted Binding Sites of TFs in the Promoter Regions of the Studied Genes}

The results showed six active transcription factors (TFs) (c-Myb, HSF, SRY, MZF1, ADR1, and Sp1) on the CpG sites of the JAK2 gene, two TFs (ADR1 and Ik-2) on the STAT5A gene, and four active TFs (cap, Sp1, GATA-1, and GATA-2) were predicted on the promoter region of the $C D 4$ gene (Figure 2).

\subsection{Relationship of DNA Methylation with mRNA Expression}

To evaluate the results of DNA methylation with the transcription levels of the genes under study, we performed real-time quantitative PCR to estimate the mRNA expression levels. The results showed that the mRNA expression was significantly higher in clinically mastitic cows compare to the healthy controls in the JAK2 gene, whereas in the STAT5A and $C D 4$ genes, the mRNA expression of mastitic cows was significantly lower than the healthy controls. Moreover, the mRNA expression and DNA methylation were negatively associated with JAK2 and CD4 genes, i.e., a higher methylation level was associated with a lower mRNA expression (Figure 3). DNA methylation in the figure below was calculated for the same cows for which mRNA expressions were analyzed. 
(a) Healthy control

TTTYGGAGATTTYYGGGTGGTTTTTGGGYGTGAGYGGG

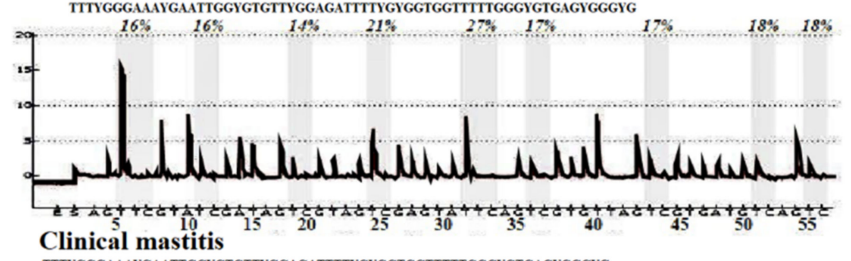

Clinical mastitis

TTTYGGGAAYYGAATTGGYGTGTTYGGAGATTTTVGYGGTGGTTTTGGGYGTGAGYGGGYG

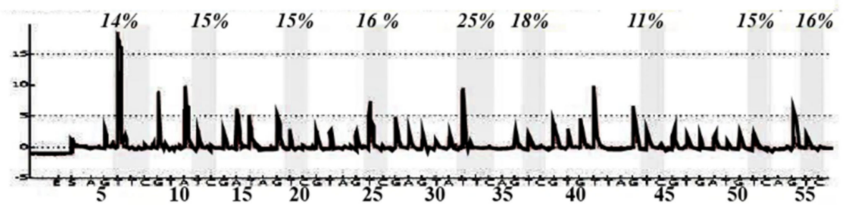

(c) Healthy control

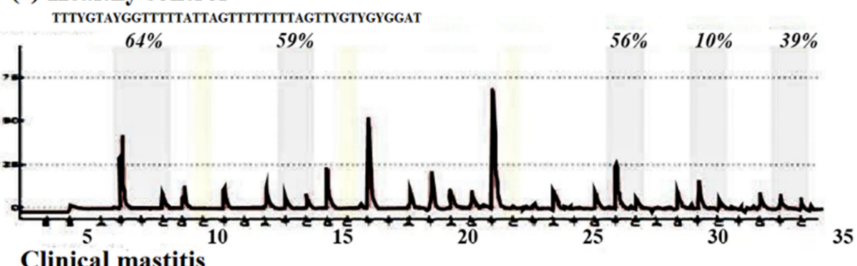

Clinical mastitis

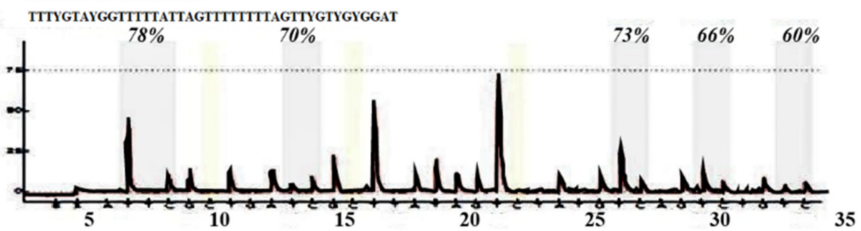

(b) Healthy control

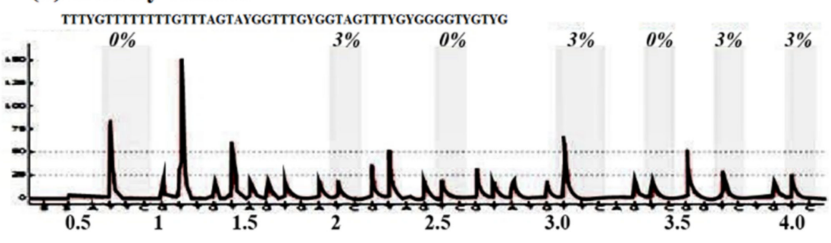

Clinical mastitis

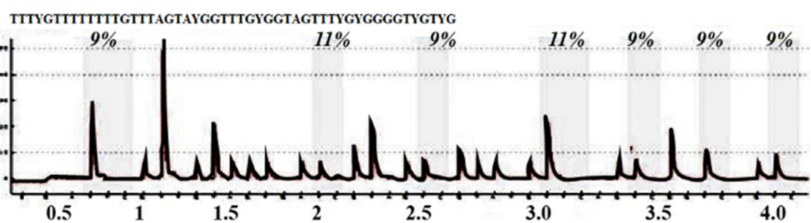

Figure 1. Results of bisulfite pyrosequencing showing aberrant methylation in clinically mastitic cow and healthy controls in almost all of the CPG sites in the genes under study: (a) JAK2, (b) STAT5A, (c) $\mathrm{CD} 4$.

Table 2. DNA methylation levels of $C P G$ sites in $1 \mathrm{~kb}$ promoter regions of the JAK2, STAT5A, and CD4 genes in clinically mastitic and healthy cows.

\begin{tabular}{ccccc}
\hline CpG Position & Gene & $\begin{array}{c}\text { Clinical Mastitis } \\
\text { (Mean } \pm \mathbf{S E )}\end{array}$ & $\begin{array}{c}\text { Healthy Control } \\
\text { (Mean } \pm \mathbf{S E )}\end{array}$ & $p$ Value \\
\hline CpG site 1 & JAK2 & $15.6 \pm 10.1$ & $25.9 \pm 15.7$ & 0.05 \\
& STAT5A & $10.3 \pm 5.7$ & $12.9 \pm 12.5$ & 0.40 \\
CpG site 2 & CD4 & $82.7 \pm 7.8$ & $75.8 \pm 5.3$ & $4 \times 10^{-3}$ \\
& JAK2 & $14.7 \pm 6.4$ & $25.5 \pm 11.5$ & $3 \times 10^{-4}$ \\
& STAT5A & $8.9 \pm 10.2$ & $10.1 \pm 6.9$ & 0.02 \\
CpG site 3 & CD4 & $68.6 \pm 3.0$ & $66 \pm 2.5$ & $7 \times 10^{-3}$ \\
& JAK2 & $13.9 \pm 5.6$ & $20.9 \pm 9.9$ & $3 \times 10^{-3}$ \\
& STAT5A & $8.8 \pm 1.7$ & $12.6 \pm 8.2$ & 0.15 \\
CpG site 4 & CD4 & $77.8 \pm 4$ & $69.5 \pm 5$ & $2 \times 10^{-5}$ \\
& JAK2 & $19 \pm 12$ & $36.5 \pm 22$ & $4 \times 10^{-3}$ \\
CpG site 5 & STAT5A & $10.3 \pm 5.6$ & $10.7 \pm 11.9$ & 0.50 \\
& CD4 & $70.1 \pm 6.3$ & $62.1 \pm 3.9$ & $1 \times 10^{-4}$ \\
& JAK2 & $25.9 \pm 17.7$ & $46.6 \pm 28.5$ & $6 \times 10^{-3}$ \\
CpG site 6 & STAT5A & $5.5 \pm 1.2$ & $7.2 \pm 1.2$ & 0.02 \\
& CD4 & $57.8 \pm 3.3$ & $54.9 \pm 5.7$ & 0.05 \\
CpG site 7 & JAK2 & $14.8 \pm 6.7$ & $23.9 \pm 10.5$ & $2 \times 10^{-3}$ \\
& STAT5A & $7.4 \pm 1.5$ & $9 \pm 2.2$ & 0.01 \\
CpG site 8 & JAK2 & $15.2 \pm 8$ & $21.8 \pm 8.5$ & 0.01 \\
\hline
\end{tabular}


Table 2. Cont.

\begin{tabular}{ccccc}
\hline CpG Position & Gene & $\begin{array}{c}\text { Clinical Mastitis } \\
\text { (Mean } \pm \text { SE) }\end{array}$ & $\begin{array}{c}\text { Healthy Control } \\
\text { (Mean } \pm \mathbf{S E )}\end{array}$ & $p$ Value \\
\hline CpG site 9 & JAK2 & $19.6 \pm 8.5$ & $24.1 \pm 11.7$ & 0.07 \\
All (Mean) & JAK2 & $17.5 \pm 9.6$ & $27.3 \pm 14.3$ & $3 \times 10^{-3}$ \\
& STAT5A & $8.7 \pm 3.8$ & $10 \pm 5.7$ & 0.20 \\
& CD4 & $71.4 \pm 3.2$ & $65.7 \pm 3.7$ & $5 \times 10^{-5}$ \\
\hline
\end{tabular}

(a) JAK2 TF
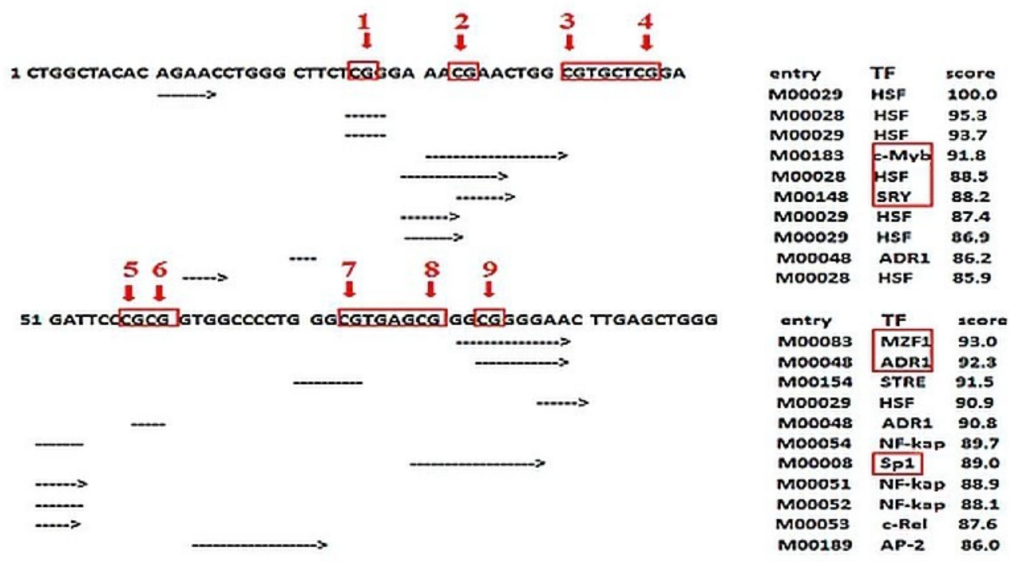

(b) STAT5A TF
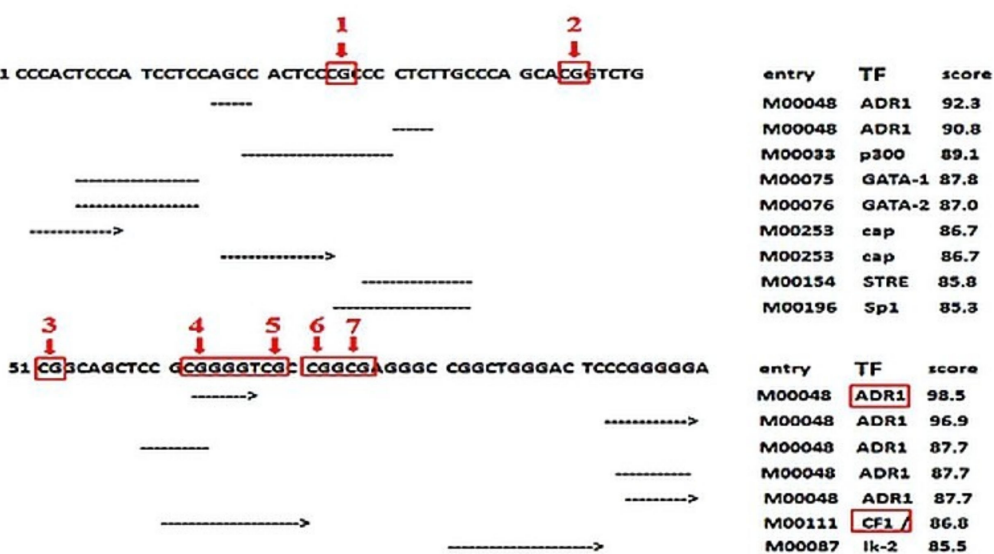

(c) CD4 TF

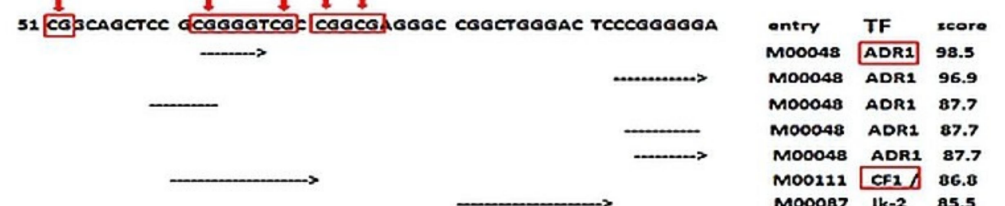

$\begin{array}{ll}1 & 2 \\ \downarrow & \downarrow\end{array}$
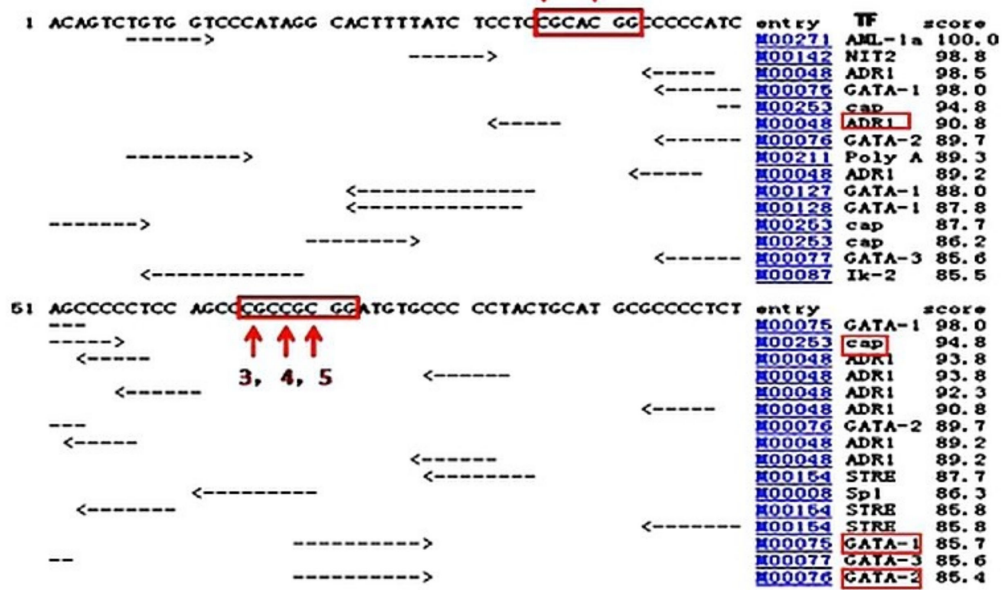

Figure 2. Predicted binding sites of transcription factors in the $1 \mathrm{~kb}$ promoter region of different genes under study: (a) JAK2, (b) STAT5A, (c) CD4. Number with red arrows indicate the CpG sites in the $1 \mathrm{~kb}$ promoter region of the studied genes. TF, predicted transcriptional factor. 
DNA Methylation

(a)

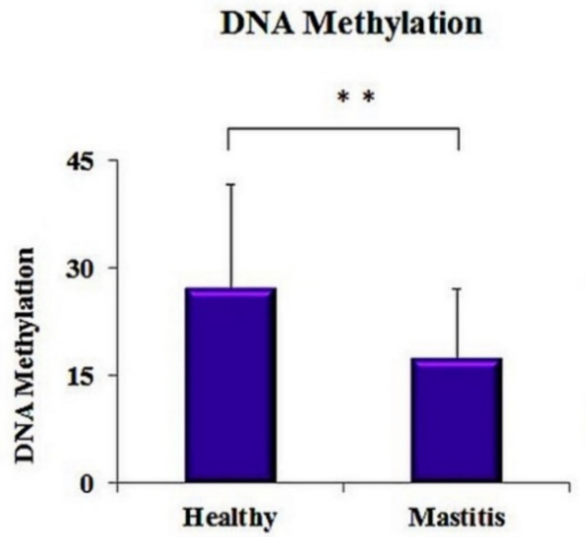

DNA Methylation

(b)

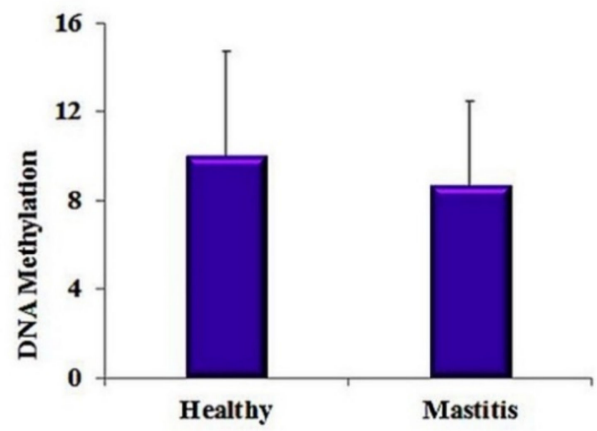

DNA methylation

(c)

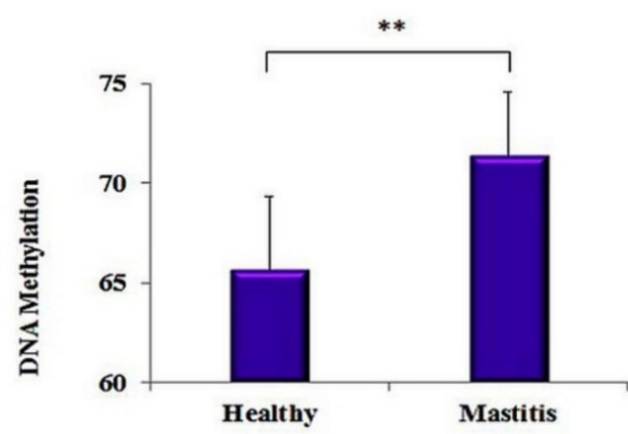

mRNA expression

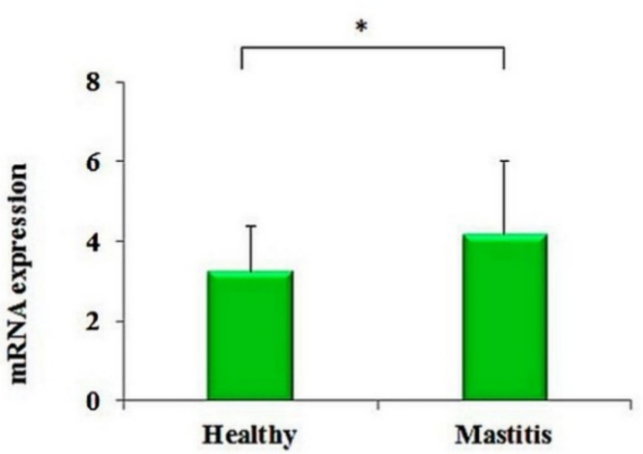

mRNA expression

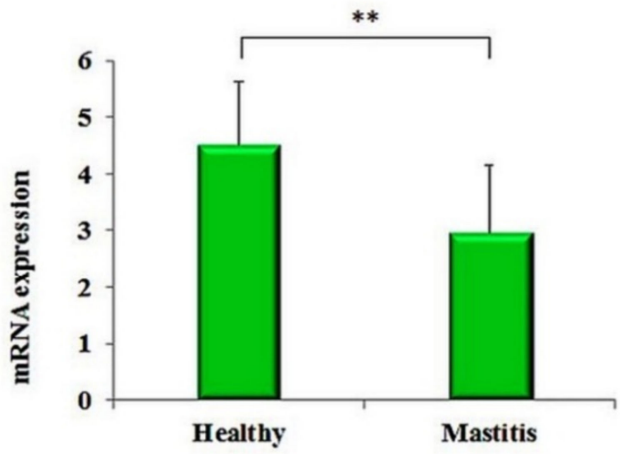

mRNA expression

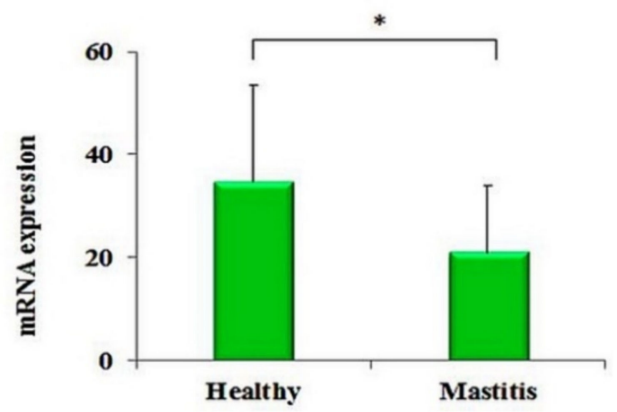

Figure 3. Results of $\mathrm{CpG}$ site methylation and mRNA expression in the clinically mastitic cows and in healthy controls: (a) JAK2 gene, (b) STAT5A gene, (c) CD4 gene. The asterisk "** symbol shows the values are significant at $(p<0.05)$ and the "***" shows that values are significant at $(p<0.01)$.

\subsection{Correlation among the $\mathrm{C} p \mathrm{G}$ Sites in the Genes under Study}

We analyzed the correlation among all of the CpG sites in CpG island of the genes under study. The results showed that almost all of the $\mathrm{CpG}$ sites were highly significantly correlated with each other in the JAK2, STAT5A, and CD4 genes (Supplementary Materials Tables S3-S5). 


\subsection{Methylation Correlation with Mastitis Traits in the Studied Genes}

The results of methylation correlations (Spearman) with mastitis indicator traits in $J A K 2$, STAT5A, and CD4 genes are shown in Table 3. The results indicated that the methylation levels of the JAK2 gene exhibited a significant association with IL-4; STAT5A was significantly associated with IL-4 and Il-17; and the methylation level of the CD4 gene was highly significantly associated with SCC, SCS, mastitis status, and IFN- $\gamma(p<0.01)$.

Table 3. Spearman's correlation of DNA methylation levels with mastitis-related traits in JAK2, STAT5A, and CD4 genes.

\begin{tabular}{cccc}
\hline Traits & JAK2 Methylation & STAT5A Methylation & CD4 Methylation \\
\hline SCC & -0.06 & 0.17 & $0.67^{* *}$ \\
$p$ value & 0.55 & 0.33 & $5 \times 10^{-4}$ \\
SCS & -0.05 & 0.15 & $0.71^{* *}$ \\
$p$ value & 0.61 & 0.41 & $3 \times 10^{-5}$ \\
Status & -0.13 & -0.24 & $0.66^{* *}$ \\
$p$ value & 0.18 & 0.16 & $2 \times 10^{-5}$ \\
IL-4 & $0.28^{*}$ & $-0.48^{*}$ & -0.15 \\
$p$ value & 0.03 & 0.03 & 0.51 \\
IL-6 & -0.04 & $-0.51^{*}$ & -0.10 \\
$p$ value & 0.73 & 0.03 & 0.65 \\
IL-10 & -0.08 & 0.14 & -0.24 \\
$p$ value & 0.56 & 0.56 & 0.31 \\
IL-17 & -0.19 & $0.44 *$ & 0.15 \\
$p$ value & 0.15 & 0.05 & 0.53 \\
TNF- $\alpha$ & 0.07 & 0.08 & -0.22 \\
$p$ value & 0.63 & 0.73 & 0.36 \\
IFN- $\gamma$ & 0.11 & -0.01 & -0.54 \\
$p$ value & 0.41 & 0.95 & 0.01 \\
\hline
\end{tabular}

The asterisk "**" symbol shows the values are significant at $(p<0.05)$, and the "*** shows that values are significant at $(p<0.01)$. SCC, somatic cell count; SCS, somatic cell score; Status, health status; IL-4, interleukin 4; IL-6, interleukin-6; IL-10, interleukin-10; IL-17, interleukin-17; TNF- $\alpha$, tumor necrosis factor-alpha; IFN- $\gamma$, interferon- $\gamma$.

\section{Discussion}

Unlike genetic variants, which cause irreparable changes in the gene and can potentially result in gene activation or other effects, epigenetic modifications are known to be reversible changes which influence gene expression whilst keeping the DNA sequence unaltered [8]. DNA methylation is the most understood mechanism amongst all of the epigenetic mechanisms and its role is well known in mediating the gene expression [18]. DNA methylation is known to be an important epigenetic modification that potentially suppresses gene expression; thus, it can play a vital role in inflammatory conditions [17-19]. In recent years, the locus-specific methylation levels in peripheral leukocytes have emerged as suitable epigenetic markers in breast cancer [26] and in various other inflammatory conditions [17-19]. It has been reported that DNA methylation patterns can serve as a stable epigenetic marker of gene silencing memory in animals [19]. One recent study suggested potential regulatory roles of DNA methylation in bovine mammary glands during S. aureus-induced mastitis [27]. Song et al. (2016) reported aberrant DNA methylation in 1078 genes in cows with subclinical mastitis vs. healthy controls; most of these genes were associated with inflammation and ErbB signaling pathway [28]. A study in mice showed that DNA methylation is quite stable across generations and the epigenetic information can be passed on for up to three generations $[19,20]$. Due to the stable nature of DNA methylation across generations and its average heritability of $0.18-0.19$ [21], it is suggested to consider it as an important epigenetic marker for selection in breeding programs. Based on the important function of DNA methylation in various inflammatory conditions in different species, its role as a potential epigenetic marker in the $1 \mathrm{~kb}$ promoter region of genes under study in the mastitis resistance of dairy cattle has been evaluated. 
We found that the methylation levels at CpG sites in the JAK2 gene in mastitic cows was significantly low and the mRNA expression was significantly higher, and vice versa in healthy controls $(p<0.05)$. This revealed that a lower methylation status of the JAK2 gene in mastitic cows possibly induces enhanced gene expression. Perez et al. (2013) reported that CpG sites in JAK2 were aberrantly methylated in myeloproliferaitve neoplasms compared with healthy controls, and $87.5 \%$ of the differentially methylated CpG sites were located in the CpG island [15]. JAK2 plays an essential role in the activation of the lmo2 leukemogenic gene through phosphorylation of the H3Y41 histone [29]. The results of the present study are in line with a previous study which reported that the methylation patterns of CpG sites in the JAK2 gene were hypomethylated after $24 \mathrm{~h}$ in $E$. coli-challenged porcine mammary epithelial cells compared with the control cells [30]. It is well documented that hypermethylation of the $\mathrm{CpG}$ island is associated with decreased mRNA expression because hyper-methylated CPG sites can block the transcription factor (TF) motifs [31,32]. The presence of six active TFs in the CpG island of the JAK2 gene in the present study shows that these TFs could have a potential role in gene activation and silencing; thus, they can play important roles in mastitis resistance. The TFs revealed in a recent study were reported to be involved in transcription activation and gene regulation [33]. The variable DNA methylation levels of $\mathrm{CpG}$ sites in the $J A K 2$ promoter region reveal that methylation at these sites could be a potential epigenetic marker for mastitis resistance. We suggest that further studies should be carried on epigenetic modifications (DNA methylation) of the JAK2 gene in dairy cattle with clinical mastitis in a larger population. In the STAT5A promoter region, the $\mathrm{CPG}$ sites exhibited higher methylation in healthy controls than mastitic cows, and the association between mRNA expression and methylation was nonsignificant. Moreover, the presence of the two active transcription factors in the CpG sites of the STAT5A gene manifest that these TFs can potentially play an important role in gene switch-on or switch-off. Stefanowicz et al. (2012) reported variable methylation between airway epithelial cells and the peripheral blood mononuclear cells [34]. DNA methylation selectively inhibits gene expression in the STAT5A gene of oncogenic cells [35]. To the best of our knowledge, this is the first epigenetic study focused on DNA methylation level evaluations in mastitic cows and healthy controls in the STAT5A gene. The results of the different DNA methylation levels, although non-significant, between the mastitic cows and the healthy controls, suggest that STAT5A could be considered in future epigenetic studies on mastitis resistance in dairy cattle.

The findings of the present study are in complete agreement with our previous study that reported hyper-methylation and lower mRNA expression in the promoter region of the CD4 gene in mastitic cows compared with healthy controls [16]. CpG island methylation in the CD4 promoter region was downregulated in a line of chickens susceptible to MDV, whereas the gene expression was upregulated in the spleen of that particular line of chicken [36]. Many studies have reported that DNA methylation influences CD4 gene silencing and plays an important role in inflammatory conditions, causing the development and differentiation of $C D 4^{+} \mathrm{T}$ cells [37]. Li et al. (2010) reported that the hyper-methylation of $\mathrm{CpG}$ sites can suppress gene expression by inactivating the transcription factor binding sites [31]. The presence of four active TFs at CpG sites of the CD4 gene indicates that these TFs might be involved in the switching on/off of the CD4 gene [31]. Hence, these results are promising, suggesting that DNA methylation at the promoter region of $C D 4$ can be considered as a potential epigenetic marker for mastitis resistance. We recommend carrying out further research to verify the functional role of DNA methylation in promoter CpG islands of the CD4 gene in mastitis resistance studies.

The results of the present study are in line with our previous study [16], although the time, individuals' samples, and the environmental conditions were totally different between the two studies. These results indicate that CD4 DNA methylation at the promoter region can be used as a potential biomarker in mastitis resistance studies. Similarly, the study of JAK2 and STAT5A methylation status, and mRNA expression in mastitic versus healthy controls, indicated the potential role of the $\mathrm{CpG}$ island at the $1 \mathrm{~kb}$ promoter region in these 
genes in hypo-methylation, and higher mRNA expression in mastitic cows compared to healthy controls in the $J A K 2$ gene. The results from TFSEARCH software revealed active transcription factors in the $\mathrm{CpG}$ sites of these genes, which indicates that variation in the TF methylation during mastitis can affect the switch-on or switch-off of the gene, thus modifying gene action.

\section{Conclusions}

The aberrant DNA methylation levels in JAK2 and CD4 genes between mastitic cows and healthy controls and their inverse relationship with gene expression suggests that these genes could be potential candidate genes of epigenetic importance. The CpG sites at the $\mathrm{CpG}$ island in the $1 \mathrm{~kb}$ promoter region of the studied genes showing peculiar methylation patterns are recommended to be studied in other populations at larger scale to validate their roles as potential biomarkers in future epigenetic studies on mastitis resistance in dairy cattle.

Supplementary Materials: The following additional supporting information may be found online at https: / / www.mdpi.com/article/10.3390/ani12010065/s1 for this article: Table S1. Information of primers used for real-time PCR; Table S2. Information of primers used for pyrosequencing assay; Table S3. Correlation amongst nine CpG sites in the JAK2 gene; Table S4. Correlation amongst seven CpG sites in the STAT5A gene; Table S5. Correlation amongst five CpG sites in the CD4 gene.

Author Contributions: Conceptualization: Y.Y. and Y.W.; methodology: T.U., Y.Y. and Y.W.; data curation: T.U., Y.Y., Y.W. and N.A.; writing: T.U.; writing-review and editing: T.U., Y.Y., Y.W. and N.A.; visualization: T.U., Y.Y., Y.W. and N.A.; supervision: T.U., Y.Y. and Y.W.; project administration: T.U. and Y.Y. All authors have read and agreed to the published version of the manuscript.

Funding: The research was funded by the NSFC-PSF Joint Project (31961143009), PSF-NSFC III/Agr/ $\mathrm{KP} / \mathrm{AWKUM} /(20)$, the Modern Agro-Industry Technology Research System (CARS-36), and the Beijing Natural Science Foundation (6182021). The funders had no role in the study design, data collection, analysis, decision to publish, or preparation of the manuscript.

Institutional Review Board Statement: The study was conducted according to the guidelines of the Declaration of Helsinki, and approved by the Animal Welfare Committee of the China Agriculture University (Permit number DK966).

Informed Consent Statement: Not applicable.

Data Availability Statement: All the data is included in the manuscript files and the Supplementary Files of this research paper.

Acknowledgments: The authors are thankful to the farm management for providing data for the present research.

Conflicts of Interest: The authors declare that they have no competing interest.

\section{References}

1. Usman, T.; Yu, Y.; Liu, C.; Wang, X.; Zhang, Q.; Wang, Y. Genetic Effects of Single Nucleotide Polymorphisms in JAK2 and STAT5A Genes on Susceptibility of Chinese Holsteins to Mastitis. Mol. Biol. Rep. 2014, 41, 8293-8301. [CrossRef] [PubMed]

2. Hogeveen, H.; Huijps, K.; Lam, T.J. Economic aspects of mastitis: New developments. N. Z. Vet. J. 2011, 59, 16-23. [CrossRef] [PubMed]

3. Hameed, K.G.A.; Sender, G.; Korwin-Kossakowska, A. Public Health Hazard Due to Mastitis in Dairy Cows. Anim. Sci. Pap. Rep. 2007, 25, 73-85.

4. Zeb, S.; Ali, N.; Niaz, S.; Rasheed, A.; Khattak, I.; Khan, N.U.; Wang, Y.; Usman, T. Association of SNPs in the Coding Regions of CD4 Gene with Mastitis Susceptibility and Production Traits in Dairy Cattle. Thai J. Vet. Med. 2020, 50, 75-80.

5. Ali, N.; Niaz, S.; Khan, N.U.; Gohar, A.; Khattak, I.; Dong, Y.; Khattak, T.; Ahmad, I.; Wang, Y.; Usman, T. Polymorphisms in JAK2 Gene Are Associated with Production Traits and Mastitis Resistance in Dairy Cattle. Ann. Anim. Sci. 2020, 20, 409-423. [CrossRef]

6. Usman, T.; Wang, Y.; Yu, Y.; Liu, C.; Wang, X.; Zhang, Y. Association Study of Single Nucleotide Polymorphisms in STAT5A/B with Mastitis Susceptibility in Chinese Holstein Cattle. In Proceedings of the 10th World Congress of Genetics Applied to Livestock Production, Vancouver, BC, Canada, 17-22 August 2014. 
7. Rasheed, A.; Ali, N.; Niaz, S.; Zeb, S.; Khattak, I.; Khan, A.; Ahmad, I.; Wang, Y.; Usman, T. Single Nucleotide Polymorphisms in the Promoter of CD4 Gene Are Associated with Production and Mastitis Traits in Dairy Cattle. Pak. Vet. J. 2020, 40, $394-396$.

8. Nowacka-Zawisza, M.; Wiśnik, E. DNA Methylation and Histone Modifications as Epigenetic Regulation in Prostate Cancer. Oncol. Rep. 2017, 38, 2587-2596. [CrossRef]

9. Ehrlich, M. DNA Hypermethylation in Disease: Mechanisms and Clinical Relevance. Epigenetics 2019, 14, 1141-1163. [CrossRef]

10. Robertson, K.D. DNA Methylation and Human Disease. Nat. Rev. Genet. 2005, 6, 597-610. [CrossRef]

11. Wu, Y.; Chen, J.; Sun, Y.; Dong, X.; Wang, Z.; Chen, J.; Dong, G. PGN and LTA from Staphylococcus aureus Induced Inflammation and Decreased Lactation through Regulating DNA Methylation and Histone H3 Acetylation in Bovine Mammary Epithelial Cells. Toxins 2020, 12, 238. [CrossRef]

12. Verma, A.; Kambhampati, S.; Parmar, S.; Platanias, L.C. Jak Family of Kinases in Cancer. Cancer Metastasis Rev. 2003, 22, $423-434$. [CrossRef]

13. Shuai, K.; Liu, B. Regulation of JAK-STAT Signalling in the Immune System. Nat. Rev. Immunol. 2003, 3, 900-911. [CrossRef]

14. Usman, T.; Wang, Y.; Liu, C.; Wang, X.; Zhang, Y.; Yu, Y. Association Study of Single Nucleotide Polymorphisms in JAK 2 and STAT 5B Genes and Their Differential MRNA Expression with Mastitis Susceptibility in Chinese Holstein Cattle. Anim. Genet. 2015, 46, 371-380. [CrossRef]

15. Pérez, C.; Pascual, M.; Martín-Subero, J.I.; Bellosillo, B.; Segura, V.; Delabesse, E.; Álvarez, S.; Larrayoz, M.J.; Rifón, J.; Cigudosa, J.C. Aberrant DNA Methylation Profile of Chronic and Transformed Classic Philadelphia-Negative Myeloproliferative Neoplasms. Haematologica 2013, 98, 1414-1420. [CrossRef]

16. Wang, X.S.; Zhang, Y.; He, Y.H.; Ma, P.P.; Fan, L.J.; Wang, Y.C.; Zhang, Y.I.; Sun, D.X.; Zhang, S.L.; Wang, C.D. Aberrant Promoter Methylation of the CD4 Gene in Peripheral Blood Cells of Mastitic Dairy Cows. Genet. Mol. Res. 2013, 12, 6228-6239. [CrossRef]

17. Day, T.K.; Bianco-Miotto, T. Common Gene Pathways and Families Altered by DNA Methylation in Breast and Prostate Cancers. Endocr.-Relat. Cancer 2013, 20, R215-R232. [CrossRef]

18. Kim, M.; Costello, J. DNA Methylation: An Epigenetic Mark of Cellular Memory. Exp. Mol. Med. 2017, 49, e322. [CrossRef]

19. Lesch, B.J.; Tothova, Z.; Morgan, E.A.; Liao, Z.; Bronson, R.T.; Ebert, B.L.; Page, D.C. Intergenerational epigenetic inheritance of cancer susceptibility in mammals. eLife 2019, 8, e39380. [CrossRef]

20. Skinner, M.K.; Ben, M.M.; Sadler-Riggleman, I.; Beck, D.; Nilsson, E.; McBirney, M.; Klukovich, R.; Xie, Y.; Tang, C.; Yan, W. Alterations in sperm DNA methylation, non-coding RNA and histone retention associate with DDT-induced epigenetic transgenerational inheritance of disease. Epigenet. Chromatin 2018, 11, 8. [CrossRef]

21. McRae, A.F.; Powell, J.E.; Henders, A.K.; Lisa, B.; Gibran, H.; Sonia, S.; Jodie, N.P.; Nicholas, G.M.; Peter, M.V.; Grant, W.M. Contribution of genetic variation to transgenerational inheritance of DNA methylation. Genome Biol. 2014, 15, 73. [CrossRef]

22. Usman, T.; Wang, Y.; Liu, C.; He, Y.; Wang, X.; Dong, Y.; Wu, H.; Liu, A.; Ying, Y. Novel SNPs in IL-17F and IL-17A genes associated with somatic cell count in Chinese Holstein and Inner-Mongolia Sanhe cattle. J. Anim. Sci. Biotechnol. $2017,8,5$. [CrossRef]

23. Michael, K.; Udvardi, T.C.; Wolf-Rüdiger, S.E. Golden Rules of Quantitative RT-PCR. Plant Cell 2008, 20, $1736-1737$.

24. Yu, Y.; Zhang, H.; Tian, F.; Zhang, W.; Fang, H.; Song, J. An Integrated Epigenetic and Genetic Analysis of DNA Methyltransferase Genes (DNMT s) in Tumor Resistant and Susceptible Chicken Lines. PLoS ONE 2008, 3, e2672. [CrossRef]

25. Yu, Y.; Zhang, H.; Tian, F.; Bacon, L.; Zhang, Y.; Zhang, W.; Song, J. Quantitative Evaluation of DNA Methylation Patterns for ALVE and TVB Genes in a Neoplastic Disease Susceptible and Resistant Chicken Model. PLoS ONE 2008, 3, e1731. [CrossRef]

26. Widschwendter, M.; Apostolidou, S.; Raum, E.; Rothenbacher, D.; Fiegl, H.; Menon, U.; Stegmaier, C.; Jacobs, I.J.; Brenner, H. Epigenotyping in Peripheral Blood Cell DNA and Breast Cancer Risk: A Proof of Principle Study. PLoS ONE 2008, 3 , e2656. [CrossRef]

27. Wang, M.; Liang, Y.; Ibeagha-Awemu, E.M.; Li, M.; Zhang, H.; Chen, Z.; Sun, Y.; Karrow, N.A.; Yang, Z.; Mao, Y. Genome-Wide DNA methylation analysis of mammary gland tissues from Chinese Holstein cows with Staphylococcus aureus induced mastitis Front. Genet. 2020, 11, 1295-1301. [CrossRef]

28. Song, M.; He, Y.; Zhou, H.; Zhang, Y.; Li, X.; Yu, Y. Combined analysis of DNA methylome and transcriptome reveal novel candidate genes with susceptibility to bovine Staphylococcus aureus subclinical mastitis. Sci. Rep. 2016, 6, 29390. [CrossRef]

29. Griffiths, D.S.; Li, J.; Dawson, M.A.; Trotter, M.W.; Cheng, Y.-H.; Smith, A.M.; Mansfield, W.; Liu, P.; Kouzarides, T.; Nichols, J. LIF-Independent JAK Signalling to Chromatin in Embryonic Stem Cells Uncovered from an Adult Stem Cell Disease. Nat. Cell Biol. 2011, 13, 13-21. [CrossRef]

30. Sajjanar, B.; Trakooljul, N.; Wimmers, K.; Siriluck, P. DNA methylation analysis of porcine mammary epithelial cells reveals differentially methylated loci associated with immune response against Escherichia coli challenge. BMC Genom. 2019, $20,623$. [CrossRef]

31. Li, W.; Sun, W.; Liu, L.; Yang, F.; Li, Y.; Chen, Y.; Fang, J.; Zhang, W.; Wu, J.; Zhu, Y. IL-32: A Host Proinflammatory Factor against Influenza Viral Replication Is Upregulated by Aberrant Epigenetic Modifications during Influenza A Virus Infection. J. Immunol. 2010, 185, 5056-5065. [CrossRef]

32. Wang, Y.; Chen, L.; Hagiwara, N.; Knowlton, A.A. Regulation of Heat Shock Protein 60 and 72 Expression in the Failing Heart. J. Mol. Cell. Cardiol. 2010, 48, 360-366. [CrossRef] [PubMed]

33. Ma, Z.-J.; Wei, Y.-P.; Zhong, J.-C.; Chen, Z.-H.; Lu, H.; Tong, Z.-B. Sequence Characterization of the 5'-Flanking Region of the GHR Gene in Tibetan Sheep. Yi Chuan Hered 2007, 29, 963-971. [CrossRef] [PubMed] 
34. Stefanowicz, D.; Hackett, T.-L.; Garmaroudi, F.S.; Günther, O.P.; Neumann, S.; Sutanto, E.N.; Ling, K.-M.; Kobor, M.S.; Kicic, A.; Stick, S.M. DNA Methylation Profiles of Airway Epithelial Cells and PBMCs from Healthy, Atopic and Asthmatic Children. PLoS ONE 2012, 7, e44213.

35. Zhang, Q.; Wang, H.Y.; Liu, X.; Wasik, M.A. STAT5A Is Epigenetically Silenced by the Tyrosine Kinase NPM1-ALK and Acts as a Tumor Suppressor by Reciprocally Inhibiting NPM1-ALK Expression. Nat. Med. 2007, 13, 1341-1348. [CrossRef] [PubMed]

36. Luo, J.; Yu, Y.; Zhang, H.; Tian, F.; Chang, S.; Cheng, H.H.; Song, J. Down-Regulation of Promoter Methylation Level of CD4 Gene after MDV Infection in MD-Susceptible Chicken Line. BMC Proc. 2011, 5, S7. [CrossRef]

37. Landolfi, M.M.T.; Scollay, R.; Parnes, J.R. Specific Demethylation of the CD4 Gene during CD4 T Lymphocyte Differentiation. Mol. Immunol. 1997, 34, 53-61. [CrossRef] 